\title{
DENATURED ALCOHOL AS A FREQUENT SOURCE OF METHANOL INTOXICATION
}

\author{
Yulichka Sabeva ${ }^{1}$, Petko Marinov $^{2}$, Sneza Zlateva ${ }^{2}$, Mariana Koleva ${ }^{1}$ \\ 1) Toxico-chemical Laboratory, Naval Hospital - Varna, Bulgaria. \\ 2) Department of Toxicology, Naval Hospital - Varna, Bulgaria.
}

\section{SUMMARY:}

Ethyl alcohol - spirit for technical designation, denatured is used mostly as dissolving agent in chemical industry and in the everyday life as a spirit for burning. It consists of $95 \%$ ethyl alcohol to which different substances are added and coloring agents to become not fit to drink. For the chemical industry the most often used substances are methyl alcohol (5-10\%); pyridine bases $(0.5 \%)$; benzol (5$10 \%)$; chloroform (5\%); acetone (10\%), petrol (1\%) and many others (4).

The spirit for burning in the household is denatured with methyl alcohol (3-4\%) or pyridine $(0.25 \%)$ and is indicated with the coloring agent methyl-violet which gives it a special blue-violet color. According to the state standards the spirit for burning has to contain not less than $94.5 \%$ ethyl alcohol and not more than $1 \%$ methyl alcohol as denaturizing agent (1).

Key words: ethyl alcohol, methyl alcohol, acute poisoning,

\section{INTRODUCTION:}

During the last years is registered an increase of the number of acute poisonings after consummation of spirit for burning is registered presenting as intoxication with methanol. A great number of these intoxications finished with death.

\section{MATERIALS AND METHODS:}

Samples from fluids from 122 bottles given from the relatives of the patient or police officers, had been analyzed. According to the previous information they contained spirit for burning in 76 cases; spirit drinks - 32; and fluids with unknown content and origin -14 .

The investigation is performed with gas chromatograph GC 5840 series II supplied with FID Headspace sampler 19395A and HP3396 Series II Integrator Hewlett Packard. An own gas chromatographic method for analysis of organic dissolving agent is used (1).

\section{RESULTS AND DISCUSSIONS:}

The data from the study show:

From 76 bottles spirit for burning, 60 (78.94\%) contained only methyl alcohol - from 15 to 99 vol. \%. In 2 of them isopropyl alcohol was found; in another two bottles2-19 vol. \% methyl alcohol and 66 vol. \% isopropyl alcohol. In 1 bottle with 78 vol. \% ethyl alcohol, methyl alcohol was 15 vol. \% -the reason for a severe acute intoxication (concentration of methanol in blood $-2,70 \mathrm{~g} / \mathrm{l}$; in urine $-3,60 \mathrm{~g} / \mathrm{l}$, without presence of ethanol).

In 10 of the bottles with unknown content high concentration of methanol was found- from 19,7 to $223,7 \mathrm{~g} / \mathrm{l}$.

The concentration of ethyl alcohol in the investigated 32 bottles of spirit drinks corresponds to the indicated on the label content.

\section{CONCLUSION:}

The results from the study show:

1. The spirit drinks sold in the trade network do not content methyl alcohol above the permissible limits, statutory by the state standards.

2. In the trade network often spurious and false spirit for burning is sold with high content of methyl alcohol. We consider that the exchange of ethyl alcohol with very toxic methyl alcohol in the spirit for burning leads to severe acute poisonings with methanol.

\section{REFERENCES:}

1. Bulgarian State Standard.6283/1067

2. Ivanov D. Book of organic chemistry 7 th edition. Science and Art, Sofia. $1967 ; 121$.

3. Sabeva Yu, Slavova V, Markova S.
Method of quantification of volative solvents in acute intoxications. Annual proceeding (Scientific papers) International Medical Association "Bulgaria” (IMAB), 1999; 5(1):52-54.
4. The Merck Index, An Encyclopedia of Chemicals, Drugs and Biologicals, 13th edition, published by Merck Research Laboratories Division of MERCK \& Co., INC., Whitehouse Station, NJ, 2001.

\section{Address for correspondence:}

Dr. Petko Marinov; Department of Toxicology, BBAL - Varna, 3, Hristo Smirnenski Str., Varna, Bulgaria; Fax: +359 52387 917; Mobile: +359 899982 700; E-mail: eurohospital.bg@abv.bg 